\title{
Correction to: Curved Fronts of Bistable Reaction-Diffusion Equations in Spatially Periodic Media
}

\author{
HongJun GuO, WAn-Tong Li, Rongsong LiU \& \\ ZHI-CHENG WANG
}

\section{Correction to: Arch Rational Mech Anal https://doi.org/10.1007/s00205-021-01711-x}

In this article the affiliation "School of Mathematics and Statistics, Lanzhou University, Lanzhou, China” for Author Zhi-Cheng Wang was missing.

Furthermore, in the footnote of the first page of this article the grant number relating to the National Natural Science Foundation of China given for Zhi-Cheng Wang was incorrectly given as 11371179 and should have been 12071193 .

The original article has been corrected.

Publisher's Note Springer Nature remains neutral with regard to jurisdictional claims in published maps and institutional affiliations.

The original article can be found online at https://doi.org/10.1007/s00205-021-01711- 


\section{HongJun Guo}

School of Mathematical Sciences, Institute for Advanced Study, Tongji University,

Shanghai

China.

e-mail: hongjun.guo@etu.univ-amu.fr

and

WAN-Tong Li and ZHI-Cheng WANG

School of Mathematics and Statistics,

Lanzhou University,

Lanzhou

China.

and

RongSONG LIU

Department of Mathematics and Statistics,

University of Wyoming,

Laramie

WY

USA.

Published online October 25, 2021

(C) The Author(s), under exclusive licence to Springer-Verlag GmbH, DE, part of Springer Nature (2021) 